\title{
Income Inequality and Chronic Health Conditions: \\ A Multilevel Analysis of the U.S. States
}

\author{
Kathryn Freeman Anderson \\ University of Houston \\ Eric Bjorklund \\ University of Arizona \\ Simone Rambotti \\ University of Arizona
}

\begin{abstract}
Recently, much scholarly work has been conducted examining the effect of rising income inequality on health outcomes. However, this work is somewhat inconclusive. Chiefly, the mechanisms which could produce such an association are still being sorted out. Further, much of this work is focused on mortality outcomes with little attention to how this process operates for actual health conditions, including chronic health problems, which are arguably now the main public health concerns of the developed world. In this study, in a series of multilevel binary logistic regression models using data from the 2005 and 2007 Behavioral Risk Factor Surveillance System (BRFSS), we examine the association between state-level income inequality, poverty, and social welfare measures on spending and policy to examine the association between these factors for three chronic health outcomes: diabetes, hypertension, and coronary heart disease. We find that income inequality is only conditionally positively related to the diagnosis of two of the three outcomes, diabetes and hypertension, and only in 2007. However, absolute poverty is related to the outcome across all three dependent variables. Additionally, certain social welfare measures attenuate the effects of both income inequality and absolute poverty, suggesting that certain welfare policies reduce this association.
\end{abstract}

KEYWORDS: income inequality; chronic health conditions; poverty; welfare policy 


\section{Income Inequality and Chronic Health Conditions: A Multilevel Analysis of the U.S. States}

\section{INTRODUCTION}

Although by no means a new issue, the link between income inequality and health has received much attention in recent years, especially through the publication of several key works on the subject (Subramanian and Kawachi 2004; Wilkinson and Pickett 2006; Kondo 2009). While most scholars point to some association between income inequality and health outcomes, there is a growing debate surrounding the mechanisms by which income inequality may affect health (Torre and Myrskylä 2014). Some scholars focus on income inequality as a more direct source of harm through relative deprivation, which may affect health in that it produces a social-psychological stress response (Wilkinson and Pickett 2009). However, others pinpoint absolute material deprivation and the experiences of poverty, which are often more prevalent in unequal societies, as the principal link to health outcomes (Mellor and Milyo 2002).

The issue of income inequality is generally much more nuanced than often proposed in this work. Income inequality is part of a complex web of market and political-institutional processes, of which both income inequality and poverty are often the result. Here, we attempt to shed some light on the multi-faceted ways in which these factors are interrelated. We test these ideas using a multi-level framework across the states of the U.S. and data from multiple sources, including principally the Behavioral Risk Factor Surveillance System (BRFSS). The BRFSS is a large, annual health survey conducted by the U.S. Centers for Disease Control (CDC), which is wellsuited to address these issues.

Further, we examine the case of chronic health conditions, which are generally the greatest public health problems in the developed world in the $21^{\text {st }}$ century. Chronic illnesses are the major cause of death and disability in the US, and among the most costly and preventable health issues (CDC 2016). In 2012, approximately one in two adults had one or more chronic health conditions, and approximately one in four adults had two or more chronic health conditions. Seven of the top ten causes of death in 2010 were chronic illnesses. Two chronic illnesses, diabetes and ischemic heart disease, had the highest impact on US spending on personal health care and public health in 2013, with a combined estimated $\$ 189.5$ billing in spending (Dieleman et al. 2016). An examination of chronic conditions is also valuable in that the majority of the literature on income inequality and heath is focused on subjective rather than objective measures of health (Pickett and Wilkinson 2015).

More specifically, in this study, we examine diabetes, hypertension, and coronary heart disease. In particular, we ask: How is income inequality related to chronic health problems in the U.S.? What other factors may explain this association? What welfare policies may mitigate this 
association? Generally, we expect that income inequality will be positively related to chronic health conditions. However, we also expect that poverty will be associated with those outcomes and may even explain the relationship between income inequality and health. Further, we expect that social welfare policies, specifically those which are meant to reduce the effects of poverty or redistribute wealth, will attenuate this association. First, we briefly review the current literature on the association between income inequality and health outcomes.

\section{BACKGROUND}

\section{Income Inequality and Chronic Illness}

The first study on the relationship between income inequality and health, published more than 30 years ago, found a cross-national association between Gini index and infant mortality and life expectancy (Rodgers 1979). More than 10 years later, the income inequality hypothesis, which posits that the income gap, independent of poverty rates and individual income, is detrimental to population health, became the focus of debates (Davey Smith 1996; Kaplan et al. 1996; Kennedy, Kawachi, and Prothrow-Stith 1996; Wilkinson 1992). Two decades later, this literature is still booming, and the debate remains unresolved. Evidence from over a hundred scientific articles has convinced some researchers to affirm that there is a causal relationship, or at least some association between inequality and adverse health (Pickett and Wilkinson 2015). However, the evidence against the income inequality hypothesis is not trivial. To some extent its relationship with health and the underlying mechanisms remain under question (Subramanian and Kawachi 2004; Wilkinson and Pickett 2006; Macinko et al. 2003). In fact, a considerable number of studies provide a conceptual criticism of the hypothesis, and fail to find empirical support for it, favoring explanations based on individual income, household income, and contextual poverty (Beckfield 2004; Fiscella and Franks 1997; Judge, Mulligan, and Benzeval 1998; Leigh and Jencks 2007; Mellor and Milyo 2002; Rambotti 2015).

More theoretically, three hypothesized pathways connect income inequality and individual health: stress, social capital, or neo-material factors. According to the status anxiety explanation, status differences become more evident with higher inequality as individuals are more apt to constantly compare themselves to higher-status others. This continuous comparison leads to chronic stress, which in turn leads to poor health (Wilkinson and Pickett 2009). The social capital explanation posits that income inequality decreases trust towards others and institutions, by deteriorating collective efficacy, the capacity to mobilize to obtain services and amenities, and the level of emotional support, reciprocal respect, and self-esteem (Kawachi et al. 1997; Kawachi and Berkman 2000). Finally the neo-material explanation focuses on public investment and social policy in determining differential levels of social resources available to the population in highly unequal contexts, which in turn affects individual health (Mellor and Milyo 2002; Soobader and 
LeClere 1999). However, these mechanisms have seldom been tested in the extant literature due to a paucity of data which actually explicitly measures such processes. For instance, status anxiety measures have been used only for cross-sectional comparisons across European countries (Layte 2012), and welfare is generally reduced to mere levels of spending.

Furthermore, in terms of empirical outcomes, the majority of the studies examining income inequality and health focus on life expectancy, mortality, and self-rated health, with only a small portion analyzing chronic illness. This represents a literature shortcoming. Chronic diseases present a strong social gradient in that their prevalence increases from higher to lower socioeconomic positions (Fleischer et al. 2011), and researchers have pointed out that these kinds of disease are more strongly related to the effect of income inequality (Wilkinson and Pickett 2008). For this reason, examining an outcome that is allegedly sensitive to income inequality represents a challenging and valuable test of any alternative explanation. Indeed, scholars invoked more systematic analyses of other more nuanced health and social outcomes (Pickett and Wilkinson 2015). Here, we examine the association between income inequality, absolute poverty, and social welfare spending and policy attributes on three chronic health outcomes: diabetes, hypertension, and coronary heart disease.

The research to date that exists on income inequality and chronic health conditions is quite mixed. Classic research on Roseto, Pennsylvania suggested the connection between closeknit communities and low rates of heart disease (Stout et al. 1964). Once increasing income gaps eroded the social fabric of the community, the rate of myocardial infarction increased (Bruhn and Wolf 2013; Egolf et al. 1992; Kawachi and Kennedy 1997; Wilkinson 1996). Recently, scholars have found adverse associations between inequality and coronary heart disease among U.S. households (Kennedy, Kawachi, and Prothrow-Stith 1996) and across U.S. states (Kawachi et al. 1997). Inequality is also related to increased risk for heart attack (Pabayo, Kawachi, and Gilman 2015), higher stroke mortality (Shi et al. 2003), cardiovascular disease, including hypertension (Diez-Roux, Link, and Northridge 2000), diabetes and obesity, with the latter increasing the risk of hypertension, cardiovascular disease, and diabetes itself (Wilkinson and Pickett 2009; Holtgrave and Crosby 2006; Pickett et al. 2005).

However, some studies find no effect of income inequality. For example, Lynch and colleagues (2001) found a null effect of income inequality on coronary heart disease, breast or prostate cancer, cirrhosis, and diabetes mortality (Lynch et al. 2001). Similarly, Sturm and Gresenz (2002) found that the effect of inequality on a number of chronic medical conditions disappears after controlling for education and family income (Sturm and Gresenz 2002). Finally, while most of these works uphold the role of relative deprivation, stress, and trust as mediating mechanisms, one paper examined the effect of local deprivation on type 2 diabetes incidence finding a pattern that is compatible with a materialistic interpretation of the inequality effect 
(Cox et al. 2007). They found that the type 2 diabetes is more common in deprived areas, but if these are spatially surrounded by less deprived areas, the incidence of diabetes is lower.

In summary, the extant published work on chronic health represents a small portion of the broader research on heath and inequality, and provides mixed support to the association between inequality and chronic illness. Thus, further investigation is warranted. None of the reviewed studies closely examines the role of policy, which this study considers. A brief introduction to state policy literature follows.

\section{Welfare Policy and Health Outcomes}

The promotion and provision of health care is a defining component in the development and expansion of the modern welfare state (Korpi 1989; Skocpol 1992). The U.S., for example, has a multitude of programs, services, and tax incentives aimed at influencing health outcomes: Medicaid, Medicare, Supplemental Nutritional Assistance Program (SNAP), Women, Infants, Children (WIC), Child Health Insurance Program (CHIP), school lunch, Health Coverage Tax Credit (HCTC), medical expense deductions, and so forth. There are also policies aimed at alleviating economic insecurity that nevertheless indirectly impact health: unemployment insurance, cash welfare (TANF), and the Earned Income Tax Credit (EITC) (Strully, Rehkopf, and Xuan 2010).

These policies "decommodify" the individual, meaning they partially de-couples one's living standards from market forces (Esping-Anderson 1990). It is imperative to stress that policy efficacy is contingent upon more than expenditure levels. For example, if social spending is operationalized as net public and private expenditures per person - thereby taking into account the effect of taxation and role of private expenditures - the United States outspends Denmark and Sweden, yet underperforms in its ability to reduce poverty (Kenworthy 2011). Part of this is inadequate policy coverage and characteristics. Another part is that private services and transfers in the U.S. go disproportionately to the non-poor. To clarify, by policy coverage, we are referring to how much of a target population is covered/served, and by characteristics, we mean policy adequacy (benefit levels and duration), inclusion (eligibility thresholds), and level of commitment, such as a state supplemental funds (Meyers, Gornick, and Peck 2001).

With this understanding of policy in mind, we conceptualize the U.S. health care system as a collection of multiple systems, as opposed to an ideal type private system (Freeman and Rothgang 2010). This fragmented reality stems from strong federalist structure of U.S. social policy, and is similar to that found in other facets of social policy such as taxation (Newman and O'Brien 2011), and low-income family policy (Meyers, Gornick, and Peck 2001; Soss et al. 2001). Taken in tandem with the substantial and longstanding patterns of health disparities, poverty, 
and inequality across U.S. states, we can see the utility of using U.S. states as benchmark from which to address our research questions.

To elaborate upon this last point, consider that there is substantial variation in the degree and nature of income inequality across U.S. states. As with state-level patterns of poverty, income inequality is reflective of state-level markets, political-institutional structure, degree and type of urbanization, and historical legacies. For example, New York, Connecticut, Mississippi, and Louisiana had the four largest Gini coefficients among U.S. states in 2007 (0.50, 0.481, 0.48, and 0.478). Beyond having similar Gini coefficients that are noticeably higher than the U.S. average (0.451), there are different underlying social forces structuring each of these levels of inequality. The financialized "top-heavy" economic structure of New York and Connecticut arguably elevates the Gini coefficient in these states. In contrast, high levels of income inequality Mississippi and Louisiana are likely influenced by a much different agricultural-rural economic structure. So while state-level income inequality is broadly associated with health outcomes, we must pay attention not only to qualitative differences, but also to the impact of poverty and political-economic structure within states (Chetty et al. 2016).

To summarize, first, there are numerous public and semi-private transfers and services designed to directly, or indirectly, influence health outcomes. Second, there is substantial U.S. sub-national variation in the structure and style of social policy and health care systems. Lastly, policy characteristics are equally as important as expenditure levels for understanding the effect of social policy on health outcomes. Any discussion of the impact of income inequality and poverty on health in the U.S. must incorporate these three points.

\section{DATA AND METHODS}

\section{Data}

As we are using a multi-level approach, we merge two data sources at two different units of analysis, the individual-level and the state-level. For the individual-level data, we use the 2005 and 2007 versions of the Behavioral Risk Factor Surveillance System (BRFSS). The BRFSS is conducted annually by the United States Centers for Disease Control (CDC) and is a stratified random telephone survey of the non-institutionalized U.S. adult population. The central aim of the survey is to monitor health behaviors and risk trends in the U.S. population. In 2005, the survey had a median response rate across all of the U.S. states of 51.5\%, and in 2007, a response rate of $50.58 \%$. We use this survey for all individual-level health and socio-demographic indicators. For data at the state-level, we use a 2004 dataset on inequality, poverty, and the state welfare policy measures compiled from multiple sources (see Appendix A). In order to merge these two sources, the BRFSS includes an identifier for the state of the respondent. 
While 2005 and 2007 are not the most recent years for which data is available, we chose to analyze these years as they both pre-date the recession, and 2007 reflects a peak business cycle year. This allows us to examine these issues without the biasing effects of the Great Recession, which would influence both measures of economic performance and poverty, as well as result in higher benefits from welfare state policies. Further, we removed Hawaii and Alaska from the analysis, as is common in research on U.S. state policies, as these states use a different set of criteria for determining the federal poverty level than those used in the 48 contiguous states. We also chose these two years of data in order to have multiple data points and two different time lags (one-year and three-year) with the state-level. As with most social factors and health, we expect there to be a delay in the effects of the state-level factors, especially when addressing chronic health measures like these, which make take time to develop. However, as a check on our choice of lag, we estimate two sets of models with two different time lag periods.

\section{Dependent Variables}

In order to examine the association between income inequality and chronic health conditions, we analyze three health outcomes available in the 2005 and 2007 versions of the BRFSS questionnaire. These include: diabetes, hypertension, and coronary heart disease. Each of these survey items was asked as a yes or no question, as to whether the respondent had been previously diagnosed by a physician with the disorder. Thus, each of these was coded as a binary outcome (1=yes, diagnosed with the disorder, $0=$ else).

\section{Independent Variables}

In order to examine the association between the various state-level factors and individual health, we include a variety of measures which we perceive as theoretically interesting given the discussion above. The first set of variables described here all come from the U.S. Census. First, included in every model is a variable for the Gini coefficient which is the most commonly used operationalization of income inequality. Although we chose this measure, the various methods of measuring income inequality are sensitive to different aspects of the income distribution, and these differences may lead to different conclusions about this association. Though we do not explore these differences here, this could be an important consideration for future research.

Next, we include a number of variables which are theoretically pertinent according to the literature review above and could potentially explain the relationship between income inequality and health. We group these variables into four conceptual categories and introduce the groups one-by-one in order to examine the effect on the outcome of these groups individually and the ways in which it intersects with income inequality. These groups include: absolute poverty, economic performance, welfare spending, and welfare policy. In the first group, we include only 
one measure, absolute poverty, as measured by the percent of people in the state living below the federal poverty line. We include this variable to examine the direct effects of poverty as form of material deprivation. In the economic performance group, we include two measures: GSP per capita, from the U.S. Census, as measured by the gross state product of a state divided by the total population of the state, and the unemployment rate, as measured by the percentage of people in the civilian workforce who are unemployed in the state. These measures both estimate the state's overall level of economic conditions.

Relating to welfare policy, we separate variables by spending and program attributes. This is meant to capture the complex nature of welfare policy and social well-being. Due to this complexity of these measures, a detailed description of the measure and source is provided in Appendix A. In the spending group, we include two measures: Public assistance spending, and Medicaid spending. Our measure of public assistance spending includes expenditures for cash programs, like TANF and state Supplemental Security Income (SSI), excluding administrative costs. We next utilize program attributes from five separate social programs: TANF maximum monthly benefit, average weekly unemployment benefit, state EITC, Medicaid eligibility, and average monthly SNAP benefit. Finally, in all models, we include a control variable for the population of the state, which is treated as continuous and logged to account for skew.

The BRFSS includes a variety of social demographic variables which were used as individual-level control variables across all of the multi-level models in the analysis. We include the variables for age, race/ethnicity, gender, education, marital status, employment status, income, and health insurance. We also control for several health-related factors and behaviors, including exercise, smoking, drinking, and whether or not the respondent is obese. ${ }^{1}$ Age (in years) and education (highest level of schooling completed) are treated as continuous variables. Gender $(1=$ female, $0=$ male), marital status $(1=$ married, $0=$ else $)$, health insurance $(1=$ insured by any public or private provider, $0=$ else), exercise $(1=$ engaged in physical exercise within the last month, $0=$ else), smoking $(1=$ currently smokes at least some, $0=$ else $)$, drinking $(1=$ consumed at least one alcoholic drink within the last 30 days, $0=$ else), and obesity ( $1=$ BMI over $30,0=$ else) are coded as binary variables. Race/ethnicity is recoded into four dummy variables: Non-Latino White (reference), Non-Latino Black, Latino (of any race), and other. Employment status is also recoded into a set of four binary variables: employed for wages (reference), self-employed, unemployed, and outside workforce. For income, we use a calculated variable from the data set which groups household income into five categories: less than $\$ 15,000, \$ 15,000$ to less than $\$ 25,000, \$ 25,000$ to less than $\$ 35,000, \$ 35,000$ to less than $\$ 50,000$, and $\$ 50,000$ or more. As a large number of respondents ( $12 \%$ in both years) have a missing value for this variable, we recoded income into a group of binary variables including all five of the response options and a sixth option of "don't know/refused " (reference=less than $\$ 15,000$ ). For interpretation purposes, we group-mean 
centered all level-1 independent variables. The descriptive statistics for all variables can be found

in Table 1. We do not include the individual-level control variables in the regression tables as they are not the focus of the analysis. These results are available upon request.

**Enter Table 1 about here**

\section{Method}

Due to the nested structure of the data, we estimate a series of multi-level binary logistic regression models for each of the three outcomes. For each dependent variable, we estimate a series of models where we add the different state-level groups of variables discussed above one-byone in order to examine the association with the outcome and the way that it may alter or mitigate the association between income inequality and the chronic health condition. In all models, we include the variable for the Gini coefficient and the state population as a control. Using this as a baseline model, we then add groups of level 2 variables. In Model 2, we add absolute poverty. In Model 3, we include GSP per capita and unemployment as measures of state economic performance. In Model 4, we include the set of variables for welfare spending. In Model 5, we include the set of variables for state welfare policies. Finally, in Model 6, we include all previous variables for the full model. We estimate each of these sets of models in the same fashion for each of the three dependent variables, and for the two years of data. All models were estimated in Stata version 14. We present the results in a set of tables, with the "A" table corresponding to the 2005 data, and the "B" table corresponding to the 2007 data. The regression results for diabetes can be found in Tables $2 \mathrm{~A}$ and $2 \mathrm{~B}$, for hypertension in Tables $3 \mathrm{~A}$ and $3 \mathrm{~B}$, and for coronary heart disease in Tables $4 \mathrm{~A}$ and $4 \mathrm{~B}$. The results in each of these tables are presented as X-standardized odds ratios for the ease of interpretation. X-standardized odds ratios are interpreted as a standard deviation change in $\mathrm{x}$, which facilitates the comparison across variables as they now all reflect the same metric, a one standard deviation change in x. Also, as the statelevel predictors are in the intercept equation, the odds ratios simply reflect a change in the average odds in the level 2 unit (Raudenbush and Bryk 2002). Further, please note that since these results are presented as odds ratios, any negative relationships are represented as an odds ratio of less than 1.

**Enter Tables 2A, 2B, 3A, 3B, 4A, and 4B about here** 


\section{RESULTS}

\section{Diabetes}

The regression results for diabetes for the two years of BRFSS data can be found in Tables 2A and 2B. First, examining the results in Table 2A from 2005 with only a one-year lag, the Gini coefficient does not appear to have a statistically significant relationship with the outcome. It is not significant across any of the six models. However, the variable for absolute poverty has a significant, strong, and positive relationship with being diagnosed with diabetes, indicating that the higher the absolute poverty rate in a state, the greater the odds of being diagnosed with diabetes. Specifically, a one standard deviation increase in absolute poverty in a state is associated with an increase in the average odds of being diagnosed with diabetes by a factor of 1.126 or $12.6 \%$. The inclusion of this variable also dramatically increases the value of the statelevel pseudo $\mathrm{R}^{2}$ value and accounts for about $33.3 \%$ of the state-level variation. Relatedly, several of the economic performance and welfare spending and policy variables are significant and negative, including GSP per capita, public assistance spending, TANF maximum benefits, the average SNAP benefit, and the average unemployment benefit. More substantively, a greater degree of state-level generosity, or higher levels of welfare support, on these measures is related to a decreased odds of being diagnosed with diabetes. The welfare policy measures in particular are substantively quite strong and explain a high level (52.8\%) of the state-level variation in the outcome according to the pseudo $\mathrm{R}^{2}$ value. Further, the inclusion of these variables in the full model slightly attenuates the relationship between absolute poverty and diabetes.

Turning to the results in Table 2B, with a three-year lag, the findings are somewhat altered. The coefficients for the other sets of variables are fairly consistent between the two years of data, with only minor differences in the magnitude of the coefficients. Only the variable for average unemployment benefit is now no longer significant in the full model (Model 6). However, the most notable change here is that the Gini coefficient is now significant in some of the models. Income inequality (Gini) is significant in Model 1, and has a relatively modest effect on the outcome. In particular, a one standard deviation increase in the Gini coefficient is related to an increase in being diagnosed with diabetes by a factor of 1.068 , or $6.8 \%$. With the inclusion of absolute poverty (Model 2), the welfare spending variables (Model 4), and in the full model (Model 6), this variable drops to non-significance, indicating that these other variables account for the effect of income inequality. The size of the effect is also mitigated with the inclusion of the welfare policy variables in Model 5. Thus, in the case of diabetes, the relationship with income inequality is not particularly strong or clear. We only observe a significant effect when using a three-year lag between the state-level and individual-level data, and this modest effect drops to non-significance with the inclusion of other, related variables. 


\section{Hypertension}

Second, the results for hypertension can be found in Tables $3 \mathrm{~A}$ and $3 \mathrm{~B}$. In these sets of models, the size and pattern of the effects of the variables is quite similar to the case of diabetes. Again, using the 2005 BRFSS data with a one-year lag, the effect of the Gini coefficient is not significant across any of the models. And, the coefficient for absolute poverty is significant and sizable. Specifically, a one standard deviation increase in the percent of people in poverty in a state is related to an increase in the average odds of being diagnosed with hypertension by a factor of 1.12 , or $12 \%$. This factor also accounts for a fairly sizable portion of the state-level variance, with a unique contribution of about $27.5 \%$. Also, as in the case of diabetes, the variables for GSP per capita, public assistance spending, TANF maximum, average SNAP benefit, and average unemployment benefit are all significant and negative, indicating that higher levels of spending and generosity for these factors is related to a decrease in the average odds of being diagnosed with hypertension. The coefficient for TANF maximum benefit in particular has a substantial effect, which is similar to diabetes as well. From Model 5, with the welfare policy measures, these factors also account for a substantial portion of the state-level variance using the pseudo $\mathrm{R}^{2}$ value, which demonstrates that these five factors explain about $47.5 \%$ of the overall state-level variation.

When examining the results with the three-year lag on the state-level variable and using the 2007 BRFSS data, the results are different than in the case of diabetes. Notably, in this case, the variable for income inequality is not significant in the gross effects, and is only significant in Model 3 when including the state-level economic performance variables. GSP per capita here is significant and negative, and appears to have a suppression effect on the Gini coefficient. The effect of the Gini was also bolstered by the inclusion of GSP per capita for diabetes as well. But, in this case, this is the only model in which is the Gini is significant, and the effect size is modest. Thus, income inequality here, even with a three-year lag, does not seem to have a strong or notable relationship with the likelihood of being diagnosed with hypertension across the U.S. states. The pattern for the other variables in these models is similar to the 2005 data, with the exception that public assistance spending is not significant in Model 4 here. Otherwise, the pattern and effect sizes are fairly similar to the 2005 data. As in the case of diabetes, though, the effect of income inequality on hypertension is not strong or clear, and it appears as though other state-level factors have a much stronger relationship to the outcome.

\section{Coronary Heart Disease}

Finally, the association between income inequality and coronary heart disease introduces further complexity to our understanding of this association. These results can be found in Tables 4A and 4B. Across both of these sets of models, it appears as though, these variables do not do as good of a job at understanding the relationship between state-level factors and coronary heart 
disease, as in the case of diabetes or hypertension. Fewer variables are significant, the magnitudes of the effects are somewhat smaller, and the pseudo $\mathrm{R}^{2}$ values are lower across all models.

However, the overall pattern is fairly similar to the other two chronic health conditions. In the set of models using 2005 data with a one-year lag (Table 4A), the variable for income inequality is not significant in any of the six models, while absolute poverty is significant and positive. In this case, the effect is slightly smaller, with a one standard deviation increase in absolute poverty leading to an increase in the average odds of being diagnosed with hypertension by a factor of 1.095, or 9.5\%. Similarly, the variables for GSP per capita, TANF maximum benefit, average SNAP benefit, and average unemployment benefit are significant and negative. Though, in the full model, only absolute poverty and average SNAP benefit remain significant, with little change to the effect of absolute poverty with the full set of variables.

When looking at the results with the three-year lag in the state-level variables, the pattern is fairly similar to the first set of models, as well as for the other two dependent variables. Here, the Gini coefficient is not significant in any of the six models, even with the inclusion of GSP per capita (though it was in some models with three-year lags for the other two outcomes). And, in Model 5, the variable for average unemployment benefit is no longer significant. In the full model, absolute poverty, TANF maximum benefit, and average SNAP benefit are all significant, but the inclusion of the welfare policy variables do not mitigate the effect of absolute poverty on the outcome. In sum, the Gini coefficient does not have a significant relationship to being diagnosed with coronary heart disease, either in the gross effects or with the inclusion of other, related variables. Thus, in this case, this outcome does not seem to be substantially patterned by income inequality. Though, absolute poverty does have a consistent and positive relationship with coronary heart disease, as with the other dependent variables. And, again, several of the welfare policy measures are negatively related to the outcome.

\section{DISCUSSION AND CONCLUSIONS}

The goal of this study is to analyze the theoretical orientations on the relationship between income inequality and chronic health conditions. The two dominant ways of understanding this association are either as a problem of relative deprivation through a socialpsychological stress process, or through the experience of absolute deprivation in that inequality is often associated with an unequal distribution of resources. The study presented here on chronic health conditions provides only limited and qualified support for the relative deprivation side of this debate, suggesting that the issue is perhaps more complex than often theorized and presented in the existing empirical literature on the subject. Furthermore, it suggests that these approaches are not mutually exclusive. Finally, it proposes that the typical measurement of welfare policy 
based solely on spending may systematically underestimate the effect of neo-material factors, which gain importance once program attributes are considered.

Here, we find that income inequality is only significant and positively related to two of the three chronic health outcomes, and only under certain conditions. In both cases, it was only significant when allowing a three-year lag between the state-level data and the individual-level data. In the case of hypertension, it was only significant with the inclusion of GSP per capita, which has a suppression effect on the variable. The coefficient is altered with the inclusion of other variables, especially absolute poverty and certain welfare measures. In the full models, income inequality was not significant across any of the dependent variables or years of data. The relationship between income inequality and these three chronic health outcomes is not particularly strong or straightforward, and appears to be conditioned by the choice of data and model specification. Thus, we only find very limited support for the income inequality hypothesis.

The other variables appear to have a stronger and steadier association with the outcomes. In particular, absolute poverty is always associated with the health outcomes. It is consistently significant across all model specifications, has a fairly sizable effect, and appears to explain a substantial portion of the state-level variation in the outcome. Its inclusion also reduces and removes the effect of income inequality. This provides support for the neo-material side of this debate. Furthermore, several of the welfare spending and policy variables have significant and strong effects across the model specifications and years of data. Specifically, the welfare policy measures for TANF maximum benefit, average SNAP benefit, and sometimes the average unemployment benefit have sizable and consistent effects in all model specifications where present. As these represent forms of cash and near-cash types of assistance, it appears as though direct forms of assistance (even compared to those which are more directly related to health care, like Medicaid) do a better job at accounting for the association between these various state-level factors and chronic health outcomes. This is also fitting with the neo-material theoretical perspective.

These findings are consistent with some previous research which shows only limited, qualified, or no support for the relative deprivation perspective (Fiscella and Franks 1997, Judge et al. 1998, Mellor and Milyo 2002), especially in the case of chronic health conditions (Cox et al. 2007; Lynch et al. 2001; Sturm and Gresenz 2002). However, we also find a stronger and more consistent association for absolute poverty and each of the three outcomes, which is a variable often overlooked in the current literature on the topic (for an exception see Holtgrave and Crosby 2006). Yet, from an associational analysis, it is unclear what specifically is producing the effect of poverty in the aggregate and health outcomes. For example, absolute poverty may be a reflection of other problematic underlying conditions at the state-level, or the effects may come from the negative ecological effect of poverty as noted in other research, especially at the neighborhood 
level (Kling, Liebman, and Katz 2007; Ludwig et al. 2011). Moreover, some extant research shows a positive association between income inequality and chronic health conditions in the U.S. (DiezRoux et al. 2000; Kennedy et al. 1996; Pabayo et al. 2015). Yet, here we only find an association for certain outcomes, and only under certain conditions, such as a three-year time lag with the dependent variable.

These divergent results suggest that these issues are clearly more nuanced than often proposed in the literature at present. This literature is generally dominated by two main theoretical camps in order to understand the association between income inequality and health outcomes - relative and absolute deprivation. However, these two perspectives are not mutually exclusive (though they are often presented as such), and it is likely that they operate in conjunction with one another. This is in keeping with the fundamental cause theoretical paradigm in medical sociology, which argues that social conditions are related to health outcomes through multiple mechanisms which produce multiple health outcomes (Link and Phelan 1995). From this general paradigm then, we should expect that income inequality has a nuanced and multifaceted relationship to health outcomes. Thus, under certain conditions, income inequality may be mechanistically linked to health outcomes through the social psychological process of relative deprivation while it may also be linked to health through the absolute conditions of poverty that are often associated with greater inequality. Future research should consider these nuances and attempt to better understand under which conditions these two mechanistic perspectives may be operating.

Furthermore, this study considers several welfare policy and spending measures, which could play an important role in understanding how to address the problems of poverty and inequality and their respective impacts on health outcomes. The extant literature on the topic seldom addresses or includes such measures. We find that several of these variables have a substantial relationship to the outcome and may mitigate the effects of both income inequality and poverty at the state level. Moreover, we find that specific features of welfare policy (such as the extent of their generosity or inclusiveness) are better indicators of these programs and the effect that they may have on these associations (versus pure spending indicators alone). Future research on the topic should include a more detailed and longitudinal examination of these policies measures in order to better understand how these key policy factors can impact these relationships over time.

Although the study presents some novel findings and added nuance to this discussion, it is not without its limitations. First, though we use lagged indicators for the state-level variables and use multiple time points as indicated by the previous literature (Kondo 2009), the health data at the individual-level are not panel data, thus we can merely test the associations between these various factors and not causal relationships. Longitudinal research offers more conclusive test of 
the predictors (Beckfield 2004). Further, while we test chronic health conditions which are pertinent to the major public health concerns in the developed world, the way in which the dependent variable items are worded suggests some bias. Each question specifies that in order to give an affirmative response, the respondent must have been officially diagnosed with the condition by a physician. This likely means that our estimates of the prevalence of these disorders are conservative as many people, especially those without access to the health care system, may have an undiagnosed disorder. Though we control for whether or not the respondent has health insurance, this does not capture all aspects of the ways in which access to the system may be conceptualized. These were the only measures available in the data, though. This is an important consideration for future research on the issue with regard to chronic health outcomes.

Despite these limitations, the study presented here provides some added layers and nuance to this ongoing discussion. Overall, these results suggest that the relationship between these different variables is quite complex, and that our current theoretical explanations of these phenomena are perhaps overly simplistic and do not account for the myriad of factors and policies which play a role in this association. Further research on the subject should more carefully consider the complex ways in which these issues relate to one another before drawing definitive conclusions about the nature of the association between income inequality and health, as well as the mechanisms by which we observe such as association. 


\section{NOTES}

1. We understand that these may also be thought of as mediating variables in that these statelevel conditions, such as poverty or inequality, may influence such health behaviors. This may be direct in that poverty may limit opportunities for healthy eating or exercise for example. Or, this effect may be indirect in that the conditions of poverty or inequality may be linked to negative coping behaviors, such as unhealthy eating, smoking, or drinking. However, as the individual-level variables are group-mean centered, they are uncorrelated with the state-level variables (Raudenbush and Bryk 2002). Thus, their inclusion would not change the relationship between the state-level indicators and the dependent variables. 


\section{REFERENCES}

Beckfield, Jason. 2004. "Does Income Inequality Harm Health? New Cross-National Evidence." Journal of Health and Social Behavior 45(3):231-48.

Bruhn, John and Stewart Wolf. 2013. The Roseto Story: An Anatomy of Health. Norman, Oklahoma: University of Oklahoma Press.

CDC. 2016. Chronic Disease Overview. Retrieved January 1, 2017

(https://www.cdc.gov/chronicdisease/overview/index.htm).

Chetty Raj, Michael Stepner Michael, Sarah Abraham, Shelby Lin, Benjamin Scuderi, Nicholas

Turner, Agustin Bergeron, and David Cutler. 2016. "The Association Between Income and Life Expectancy in the United States, 2001-2014." Journal of the American Medical Association 315(16):1750-1766.

Cox, Matthew, Paul J. Boyle, Peter G. Davey, Zhiqiang Feng, and Andrew D. Morris. 2007.

"Locality Deprivation and Type 2 Diabetes Incidence: A Local Test of Relative

Inequalities." Social Science \&3 Medicine 65(9)1953-64.

Davey Smith, George. 1996. "Income Inequality and Mortality: Why Are They Related?" British Medical Journal 312:987-988.

Dieleman, Joseph L. et al. 2016. "US Spending on Personal Health Care and Public Health, 19962013." Journal of the American Medical Association 316(24):2627-46.

Diez-Roux, Ana V., Bruce G. Link, and Mary E. Northridge. 2000. "A Multilevel Analysis of Income Inequality and Cardiovascular Disease Risk Factors." Social Science \& Medicine $50(5): 673-87$.

Egolf, Brenda, Judith Lasker, Stewart Wolf, and Louise Potvin. 1992. "The Roseto Effect: A 50Year Comparison of Mortality Rates." American Journal of Public Health 82(8):1089-92.

Esping-Anderson, Gøsta. 1990. The Three Worlds of Welfare Capitalism. New Jersey: Princeton University Press.

Fiscella, Kevin and Peter Franks. 1997. "Poverty or Income Inequality as Predictor of Mortality: Longitudinal Cohort Study." British Medical Journal 314(7096):1724.

Fleischer, Nancy L., Ana V. Diez Roux, Marcio Alazraqui, Hugo Spinelli, and Fernando De Maio. 2011. "Socioeconomic Gradients in Chronic Disease Risk Factors in Middle- Income Countries: Evidence of Effect Modification by Urbanicity in Argentina." American Journal of Public Health 101(2):294-301.

Freeman, Richard, and Heinz Rothgang. 2010. "Health." In pp. 367-377 of Castles, Francis G., Stephan Leibfried, Jane Lewis, Herbert Obinger, and Christopher Pierson (Eds.) The Oxford Handbook of the Welfare State. New York: Oxford University Press. 
Holtgrave, David R., and Richard Crosby. 2006. "Is Social Capital a Protective Factor against Obesity and Diabetes? Findings From an Exploratory Study." Annals of Epidemiology 16(5):406-8.

Judge, Ken, Jo-Ann Mulligan, and Michaela Benzeval. 1998. "Income Inequality and Population Health." Social Science \& Medicine 46(4-5):567-79.

Kaplan, George A., Elsie R. Pamuk, John W. Lynch, Richard D. Cohen, and Jennifer L. Balfour. 1996. "Inequality in Income and Mortality in the United States: Analysis of Mortality and Potential Pathways." British Medical Journal 312:999-1003.

Kawachi, Ichiro, and Lisa F. Berkman. 2000. "Social Cohesion, Social Capital, and Health." In pp. 174-190 of Kawachi, Ichiro, and Lisa F. Berkman (Eds,) Social Epidemiology. Oxford: Oxford University Press.

Kawachi, Ichiro and Bruce P. Kennedy. 1997. "Socioeconomic Determinants of Health : Health and Social Cohesion: Why Care about Income Inequality?" British Medical Journal 314:1037-1040.

Kawachi, Ichiro, Bruce P. Kennedy, Kimberly Lochner, and Deborah Prothrow-Stith. 1997. "Social Capital, Income Inequality, and Mortality." American Journal of Public Health 87(9):1491-98.

Kennedy, Bruce P., Ichiro Kawachi, and Deborah Prothrow-Stith. 1996. "Income Distribution and Mortality: Cross Sectional Ecological Study of the Robin Hood Index in the United States." British Medical Journal 312:1004-7.

Kenworthy, Lane and Jonas Pontusson. 2005. "Rising Inequality and the Politics of Redistribution in Affluent Countries." Perspectives on Politics 3(3):449-71.

Kenworthy, Lane. 2011. Progress for the Poor. New York: Oxford University Press.

Kling, Jeffrey R., Jeffrey B. Liebman, and Lawrence F. Katz. 2007. "Experimental Analysis of Neighborhood Effects." Econometrica 75(1):83-119.

Kondo, Naoki. (2009). "Income Inequality, Mortality, and Self Rated Health: Meta-analysis of Multilevel Studies." British Medical Journal 339:b4471.

Korpi, Walter. 1989. "Power, Politics, and State Autonomy in the Development of Social Citizenship-Social Rights during Sickness in 18 OECD Countries since 1930." American Sociological Review 54:309-28.

Layte, Richard. 2012. "The Association between Income Inequality and Mental Health: Testing Status Anxiety, Social Capital, and Neo-Materialist Explanations." European Sociological Review 28(4):498-511.

Link, Bruce G., and Jo Phelan. 1995. "Social Conditions as Fundamental Causes of Disease." Journal of Health and Social Behavior 35:80-94. 
Leigh, Andrew and Christopher Jencks. 2007. "Inequality and Mortality: Long-Run Evidence from a Panel of Countries." Journal of Health Economics 26(1):1-24.

Ludwig, Jens et al. 2011. "Neighborhoods, Obesity, and Diabetes - a Randomized Social Experiment." New England Journal of Medicine 365(16):1509-19.

Lynch, John, George Davey Smith, Marianne Hillemeier, Mary Shaw, Trivellore Raghunathan, and George A. Kaplan. 2001. "Income Inequality, the Psychosocial Environment, and Health: Comparisons of Wealthy Nations." The Lancet 358:194-200.

Macinko, James A., Leiyu Shi, Barbara Starfield, and John T. Wulu. 2003. "Income Inequality and Health: A Critical Review of the Literature." Medical Care Research and Review 60(4):407-52.

Mellor, Jennifer, and Jeffrey Milyo. 2002. "Income Inequality and Health Status in the United States: Evidence from the Current Population Survey." Journal of Human Resources 510539.

Meyers, Marcia K., Janet C. Gornick, and Laura R. Peck. 2001. "Packaging Support for LowIncome Families: Policy Variation across the United States." Journal of Policy Analysis and Management 20:457-483.

Newman, Katherine S., and Rourke L. O'Brien. 2011. Taxing the Poor: Doing Damage to the Truly Disadvantaged. Berkeley, CA: University of California Press.

Pabayo Roman, Ichiro Kawachi, and Stephen E. Gilman. 2015. "US State-level income inequality and risks of heart attack and coronary risk behaviors: longitudinal findings." International Journal of Public Health 60(5):573-88.

Pickett, Kate E., Shona Kelly, Eric Brunner, Tim Lobstein, and Richard G. Wilkinson. 2005. "Wider Income Gaps, Wider Waistbands? An Ecological Study of Obesity and Income Inequality." Journal of Epidemiology and Community Health 59(8):670-74.

Pickett, Kate E. and Richard G. Wilkinson. 2015. "Income Inequality and Health: A Causal Review." Social Science \& Medicine 128:316-26.

Rambotti, Simone. 2015. "Recalibrating the Spirit Level: An Analysis of the Interaction of Income Inequality and Poverty and Its Effect on Health." Social Science \& Medicine 139:123-31.

Raudenbush, Stephen W. and Anthony S. Bryk. 2002. Hierarchical Linear Models: Applications and Data Analysis Methods, $2^{\text {nd }}$ Edition. Thousand Oaks, CA: Sage.

Ringen, Stein. 1986. "Poverty in the Welfare State?" International Journal of Sociology 122-38.

Rodgers, G.B. 1979. "Income and Inequality as Determinants of Mortality: An International Cross-Section Analysis." Population Studies 33(2):343-51.

Skocpol, Theda. 1992. Protecting Soldiers and Mothers: The Political Origins of Social Policy in the United States. Cambridge: Harvard University Press. 
Shi, Leiyu, James Macinko, Barbara Starfield, Jiahong Xu, and Robert Politzer. 2003. "Primary

Care, Income Inequality, and Stroke Mortality in the United States A Longitudinal Analysis, 1985-1995." Stroke 34(8):1958-64.

Soobader, Mah-Jabeen and Felicia B. LeClere. 1999. "Aggregation and the Measurement of Income Inequality: Effects on Morbidity." Social Science $\&$ Medicine 48(6):733-44.

Soss, Joe, Sanford Schram, Thomas P. Vartanian, and Erin O'Brien. 2001. "Setting the Terms of Relief: Explaining State Policy Choices in the Devolution Evolution." American Journal of Political Science 42:378-95.

Stout, Clarke, Jerry Morrow, Edward N. Brandt, and Steward Wolf. 1964. "Unusually Low Incidence of Death from Myocardial Infarction: Study of an Italian American Community in Pennsylvania." Journal of the American Medical Association 188(10):845-49.

Strully, Kate, David Rehkopf, and Ximing Xuan. 2010. "The effects of prenatal poverty on infant health: State earned income tax credits and birth weight." American Sociological Review $75(4): 534-563$.

Sturm, Roland, and Carole R. Gresenz. 2002. "Relations of Income Inequality and Family Income to Chronic Medical Conditions and Mental Health Disorders: National Survey." British Medical Journal 324:20-23.

Subramanian, S. V. and Ichiro Kawachi. 2004. "Income Inequality and Health: What Have We Learned so Far?" Epidemiologic Reviews 26(1):78-91.

Torre, Roberta and Mikko Myrskylä. 2014. "Income Inequality and Population Health: An Analysis of Panel Data for 21 Developed Countries, 1975-2006." Population Studies 68(1):1-13.

Wilkinson, Richard G. 1992. "Income Distribution and Life Expectancy." British Medical Journal 304:165-68.

Wilkinson, Richard G. 1996. Unhealthy Societies: The Afflictions of Inequality. New York: Routledge.

Wilkinson, Richard G., and Kate E. Pickett. 2006. "Income Inequality and Population Health: A Review and Explanation of the Evidence." Social Science $\mathcal{E}$ Medicine 62(7):1768-84.

Wilkinson, Richard G., and Kate E. Pickett. 2008. "Income Inequality and Socioeconomic Gradients in Mortality." American Journal of Public Health 98(4):699-704.

Wilkinson, Richard G., and Kate E. Pickett. 2009. The Spirit Level: Why Greater Equality Makes Societies Stronger. New York, NY: Bloomsbury Press. 
APPENDIX A. Variable Descriptions and Sources for State-Level Welfare Spending and Policy Data

\begin{tabular}{|c|c|c|}
\hline Variable Name & Description and Coding & Source \\
\hline \multicolumn{3}{|l|}{ Expenditures: } \\
\hline Public & Public assistance expenditures as a percent of total state & National Association of State \\
\hline Assistance & expenditures, per state, in FY2004 & Budget Officers \\
\hline \multicolumn{3}{|l|}{ Spending } \\
\hline Medicaid & Medicaid expenditures as a percent of total state & National Association of State \\
\hline Spending & expenditures, per state, in FY2004 & Budget Officers \\
\hline \multicolumn{3}{|c|}{ Program Attributes: } \\
\hline $\begin{array}{l}\text { Max TANF } \\
\text { Benefit }\end{array}$ & $\begin{array}{l}\text { Maximum monthly TANF benefit (single parent family of } \\
\text { three) in } 2004\end{array}$ & $\begin{array}{l}\text { Urban Institute, Welfare Rules } \\
\text { Handbook }\end{array}$ \\
\hline $\begin{array}{l}\text { Avg Unemp } \\
\text { Benefit }\end{array}$ & $\begin{array}{l}\text { Average weekly unemployment insurance benefit, per } \\
\text { recipient, in } 2004\end{array}$ & U.S. Department of Labor \\
\hline State EITC & $\begin{array}{l}\text { Presence of supplemental state operated EITC program in } \\
2004\end{array}$ & $\begin{array}{l}\text { The Hatcher Group, "Tax } \\
\text { Credits for Working Families" }\end{array}$ \\
\hline $\begin{array}{l}\text { Medicaid } \\
\text { Eligibility }\end{array}$ & $\begin{array}{l}\text { State Medicaid income threshold for a non-working parent as } \\
\text { a percentage of the federal poverty line for a family of three } \\
\text { in } 2004\end{array}$ & Kaiser Family Foundation \\
\hline $\begin{array}{l}\text { Avg SNAP } \\
\text { Benefit }\end{array}$ & Average household monthly SNAP benefit in FY2004 & U.S. Department of Agriculture \\
\hline
\end{tabular}


TABLE 1. Descriptive Statistics for Variables Used in Binary Logistic Regression Models

\begin{tabular}{|c|c|c|c|c|c|c|}
\hline \multirow[b]{2}{*}{ Variable Name } & \multicolumn{2}{|c|}{2005} & \multicolumn{2}{|c|}{2007} & \multirow[b]{2}{*}{ Range } & \multirow[b]{2}{*}{ Description } \\
\hline & Mean & $\mathrm{SD}$ & Mean & $\mathrm{SD}$ & & \\
\hline \multicolumn{7}{|l|}{ Dependent Variables } \\
\hline Diabetes & 0.09 & 0.29 & 0.11 & 0.31 & 0 to 1 & $1=$ diagnosed with diabetes, $0=$ else \\
\hline Hypertension & 0.32 & 0.47 & 0.36 & 0.48 & 0 to 1 & $1=$ diagnosed with hypertension, $0=$ else \\
\hline Coronary Heart Disease & 0.06 & 0.23 & 0.06 & 0.24 & 0 to 1 & $\begin{array}{l}1=\text { diagnosed with coronary heart disease, } \\
0=\text { else }\end{array}$ \\
\hline
\end{tabular}

$\underline{\text { Independent Variables }}$

Individual-Level

\begin{tabular}{|c|c|c|c|c|c|c|}
\hline Age & 51.68 & 17.10 & 54.14 & 16.78 & 18 to 99 & Age in years \\
\hline \multicolumn{7}{|l|}{ Race } \\
\hline White (reference) & 0.82 & 0.38 & 0.82 & 0.38 & 0 to 1 & $1=$ White, $0=$ else \\
\hline Black & 0.07 & 0.26 & 0.07 & 0.26 & 0 to 1 & $1=$ Black, $0=$ else \\
\hline Latino & 0.06 & 0.23 & 0.06 & 0.24 & 0 to 1 & $1=$ Latino, $0=$ else \\
\hline Other Race & 0.05 & 0.21 & 0.05 & 0.21 & 0 to 1 & $1=$ other race, $0=$ else \\
\hline Female & 0.61 & 0.49 & 0.62 & 0.49 & 0 to 1 & $1=$ female, $0=$ male \\
\hline Education & 14.09 & 3.20 & 14.14 & 3.21 & 0 to 18 & $\begin{array}{l}0=\text { no school, } 5=\text { elementary, } 10=\text { some high } \\
\text { school, } 12=\text { high school, } 14=\text { some college, } \\
18=\text { college graduate }\end{array}$ \\
\hline Marital Status & 0.56 & 0.50 & 0.56 & 0.50 & 0 to 1 & $1=$ married, $0=$ else \\
\hline \multicolumn{7}{|l|}{ Employment Status } \\
\hline Employed (ref.) & 0.48 & 0.50 & 0.45 & 0.50 & 0 to 1 & $1=$ employed for wages, $0=$ else \\
\hline Self-Employed & 0.09 & 0.28 & 0.09 & 0.28 & 0 to 1 & $1=$ self-employed, $0=$ else \\
\hline Unemployed & 0.04 & 0.20 & 0.04 & 0.19 & 0 to 1 & $1=$ unemployed/out of work, $0=$ else \\
\hline Outside Workforce & 0.39 & 0.49 & 0.43 & 0.49 & 0 to 1 & $\begin{array}{l}1=\text { homemaker } / \text { student } / \text { retired/unable to } \\
\text { work, } 0=\text { else }\end{array}$ \\
\hline \multicolumn{7}{|l|}{ Income } \\
\hline$<\$ 15,000$ (ref.) & 0.10 & 0.30 & 0.09 & 0.29 & 0 to 1 & $1=$ less than $\$ 15,000,0=$ else \\
\hline$\$ 15,000$ to $\$ 25,000$ & 0.16 & 0.37 & 0.15 & 0.36 & 0 to 1 & $1=\$ 15,000$ to $\$ 25,000,0=$ else \\
\hline$\$ 25,000$ to $\$ 35,000$ & 0.12 & 0.33 & 0.11 & 0.32 & 0 to 1 & $1=\$ 25,000$ to $\$ 35,000,0=$ else \\
\hline$\$ 35,000$ to $\$ 50,000$ & 0.15 & 0.36 & 0.14 & 0.35 & 0 to 1 & $1=\$ 35,000$ to $\$ 50,000,0=$ else \\
\hline$\$ 50,000$ or More & 0.34 & 0.47 & 0.38 & 0.49 & 0 to 1 & $1=\$ 50,000$ or more, $0=$ else \\
\hline Don’t Know/Refused & 0.12 & 0.33 & 0.12 & 0.33 & 0 to 1 & $1=$ don't know $/$ refused, $0=$ else \\
\hline Insured & 0.88 & 0.33 & 0.88 & 0.32 & 0 to 1 & $1=$ health insurance, $0=$ else \\
\hline Exercise & 0.74 & 0.44 & 0.74 & 0.44 & 0 to 1 & $\begin{array}{l}1=\text { exercised at least once in past month, } \\
0=\text { else }\end{array}$ \\
\hline
\end{tabular}




\begin{tabular}{|c|c|c|c|c|}
\hline Smoker & 0.20 & 0.19 & 0 to 1 & $1=$ smokes at least sometimes, $0=$ else \\
\hline Drinker & 0.51 & 0.50 & 0 to 1 & $\begin{array}{l}1=\text { at least one drink in past } 30 \text { days, } \\
0=\text { else }\end{array}$ \\
\hline Obese & 0.26 & 0.27 & 0 to 1 & $1=$ obese $(\mathrm{BMI}>30), 0=$ else \\
\hline Variable Name & Mean & $\mathrm{SD}$ & Range & Description \\
\hline \multicolumn{5}{|l|}{ State-Level } \\
\hline Log Population & 15.18 & 1.00 & 13.19 to 17.41 & Log of state population \\
\hline Gini Coefficient & 0.44 & 0.02 & 0.35 to 0.49 & State Gini coefficient (income inequality) \\
\hline Absolute Poverty & 12.84 & 3.27 & 7.6 to 21.6 & Percent below federal poverty line \\
\hline GSP per Capita & 38687.82 & 6591.17 & 26886 to 61959 & Gross state product per capita \\
\hline Unemployment Rate & 5.14 & 0.93 & 3.4 to 7.4 & State average unemployment rate \\
\hline Medicaid Spending & 21.68 & 5.86 & 8.8 to 35.2 & $\begin{array}{l}\text { Medicaid expenditures as a percentage of } \\
\text { total state expenditures }\end{array}$ \\
\hline $\begin{array}{l}\text { Public Assistance } \\
\text { Spending }\end{array}$ & 1.40 & 1.15 & 0.3 to 6.3 & $\begin{array}{l}\text { Public assistance expenditures as a } \\
\text { percentage of total state expenditures }\end{array}$ \\
\hline TANF Maximum & 401.31 & 141.70 & 170 to 723 & $\begin{array}{l}\text { Maximum TANF monthly benefit for } \\
\text { family of three }\end{array}$ \\
\hline Avg SNAP Benefit & 192.77 & 19.08 & 153.61 to 231.69 & $\begin{array}{l}\text { Average monthly SNAP benefit per } \\
\text { household }\end{array}$ \\
\hline Medicaid Eligibility & 75.98 & 65.73 & 13 to 275 & $\begin{array}{l}\text { Medicaid income threshold for non- } \\
\text { working parent as a percentage of the } \\
\text { federal poverty line }\end{array}$ \\
\hline Avg Unemp Benefit & 248.77 & 40.32 & 171.87 to 351.35 & Average weekly unemployment benefit \\
\hline State EITC & 0.31 & 0.47 & 0 to 1 & $\begin{array}{l}1=\text { Presence of supplemental state } \\
\text { Operated EITC Program; } 0=\text { Absence }\end{array}$ \\
\hline
\end{tabular}

Note. 2005 Level $1 \mathrm{~N}=313,631$. 2007 Level $1 \mathrm{~N}=379,673$. Level $2 \mathrm{~N}=48$.

Level 1 data come from the 2005 and 2007 Behavioral Risk Factor Surveillance System.

Level 2 data come from multiple sources (see Appendix A). 
TABLE 2A. X-Standardized Odds Ratios and (Z-Ratios) for Multilevel Binary Logistic Regression Models of Diabetes in 2005

\begin{tabular}{|c|c|c|c|c|c|c|c|c|c|c|c|c|}
\hline \multirow[b]{2}{*}{ Variable Name } & \multicolumn{2}{|c|}{ Model 1} & \multicolumn{2}{|c|}{ Model 2} & \multicolumn{2}{|c|}{ Model 3} & \multicolumn{2}{|c|}{ Model 4} & \multicolumn{2}{|c|}{ Model 5} & \multicolumn{2}{|c|}{ Model 6} \\
\hline & OR & Z-Ratio & OR & Z-Ratio & OR & Z-Ratio & OR & Z-Ratio & OR & Z-Ratio & OR & Z-Ratio \\
\hline
\end{tabular}

\section{Fixed Effects:}

\section{Level 2 Variables}

Log Population

Gini Coefficient

$\begin{array}{lllr}1.037 & (1.18) & 1.046 & (1.82) \\ 1.042 & (1.35) & 0.996 & (-0.15) \\ & & 1.126^{* * *} & (5.07)\end{array}$

$\begin{array}{ll}1.041 & (1.29) \\ 1.052 & (1.83) \\ & \\ 0.912^{* * *} & (-3.44) \\ 1.002 & (0.06)\end{array}$

$\begin{array}{ll}1.044 & (1.56) \\ 1.030 & (1.03) \\ & \\ & \\ & \\ 1.044 & (1.62) \\ 0.923^{* *} & (-3.28)\end{array}$

$\begin{array}{lrlr}1.082^{* * *} & (3.50) & 1.095^{* * *} & (3.72) \\ 1.020 & (0.98) & 0.990 & (-0.43) \\ & & 1.107^{* *} & (2.93) \\ & & 1.024 & (0.88) \\ & & 0.979 & (-0.82) \\ & & 1.003 & (0.14) \\ & & 0.992 & (-0.35) \\ 0.887^{* * *} & (-4.58) & 0.904^{* *} & (-3.27) \\ 0.931^{* *} & (-2.95) & 0.914^{* * *} & (-3.65) \\ 1.005 & (0.22) & 1.003 & (0.16) \\ 0.915^{* * *} & (-3.50) & 0.939^{*} & (-2.33) \\ 1.013 & (0.61) & 1.016 & (0.84) \\ & & & \end{array}$

GSP per Capita

Unemployment Rate

Medicaid Spending

Public Assistance

TANF Maximum

Avg SNAP Benefit

Medicaid Eligibility

Avg Unemployment Benefit

State EITC

\section{Random Effect:}

Intercept Variance

0.032

0.020

0.024

0.025

0.013

0.010

Level 2 Pseudo $\mathrm{R}^{2}$

0.111

0.444

\subsection{0 \\ 164370.600}

\author{
0.639 \\ 164072.400 \\ 164381.400
}

0.722

164072.600

164434.900

Note: Level $1 \mathrm{~N}=313,631$. Level $2 \mathrm{~N}=48$. The models also include individual-level independent variables and constants. OR=Odds ratio (factor change).

${ }^{*} \mathrm{p}<.05,{ }^{* *} \mathrm{p}<.01,{ }^{* * *} \mathrm{p}<.001$ (two-tailed). The Level 2 Pseudo $\mathrm{R}^{2}$ is the proportion reduction in the intercept variable from a model with only level 1 variables to the current model. The intercept variance for model with only level 1 variables is: 0.036 . 
TABLE 2B. X-Standardized Odds Ratios and (Z-Ratios) for Multilevel Binary Logistic Regression Models of Diabetes in 2007

\begin{tabular}{|c|c|c|c|c|c|c|c|c|c|c|c|c|}
\hline \multirow[b]{2}{*}{ Variable Name } & \multicolumn{2}{|c|}{ Model 1} & \multicolumn{2}{|c|}{$\underline{\text { Model } 2}$} & \multicolumn{2}{|c|}{ Model 3} & \multicolumn{2}{|c|}{ Model 4} & \multicolumn{2}{|c|}{ Model 5} & \multicolumn{2}{|c|}{ Model 6} \\
\hline & OR & Z-Ratio & OR & Z-Ratio & OR & Z-Ratio & OR & Z-Ratio & OR & Z-Ratio & OR & Z-Ratio \\
\hline
\end{tabular}

Fixed Effects:

\section{Level 2 Variables}

Log Population

Gini Coefficient

$\begin{array}{llll}1.055 & (1.68) & 1.065^{*} & (2.41) \\ 1.068^{*} & (2.04) & 1.019 & (0.67) \\ & & 1.126^{* * *} & (4.79)\end{array}$

$\begin{array}{ll}1.066 & (1.95) \\ 1.081^{* *} & (2.63) \\ & \\ 0.912^{* * *} & (-3.38) \\ 0.990 & (-0.31)\end{array}$

$\begin{array}{ll}1.061^{*} & (1.96) \\ 1.058 & (1.81) \\ & \\ & \\ 1.035 & (1.19) \\ 0.934^{*} & (-2.54)\end{array}$

$\begin{array}{llll}1.092^{* * *} & (3.45) & 1.110^{* * *} & (3.75) \\ 1.047^{*} & (1.96) & 1.020 & (0.72) \\ & & 1.104^{*} & (2.48) \\ & & 1.012 & (0.36) \\ & & 0.968 & (-1.10) \\ & & 0.997 & (-0.12) \\ & & 1.013 & (0.49) \\ 0.890^{* * *} & (-3.90) & 0.894^{* *} & (-3.18) \\ 0.944^{*} & (-2.10) & 0.923^{* *} & (-2.83) \\ 0.983 & (-0.67) & 0.984 & (-0.63) \\ 0.939 * & (-2.20) & 0.963 & (-1.22) \\ 1.006 & (0.24) & 1.014 & (0.62)\end{array}$

State EITC

\section{Random Effect:}

Intercept Variance

0.036

0.023

0.028

0.030

0.018

0.014

Level 2 Pseudo $\mathrm{R}^{2}$

0.217

0.500

0.391 
TABLE 3A. X-Standardized Odds Ratios and (Z-Ratios) for Multilevel Binary Logistic Regression Models of Hypertension in 2005

\begin{tabular}{|c|c|c|c|c|c|c|c|c|c|c|c|c|}
\hline \multirow[b]{2}{*}{ Variable Name } & \multicolumn{2}{|c|}{ Model 1} & \multicolumn{2}{|c|}{ Model 2} & \multicolumn{2}{|c|}{ Model 3} & \multicolumn{2}{|c|}{ Model 4} & \multicolumn{2}{|c|}{$\underline{\text { Model } 5}$} & \multicolumn{2}{|c|}{$\underline{\text { Model } 6}$} \\
\hline & OR & Z-Ratio & OR & Z-Ratio & OR & Z-Ratio & OR & Z-Ratio & OR & Z-Ratio & OR & Z-Ratio \\
\hline
\end{tabular}

\section{Fixed Effects:}

\section{Level 2 Variables}

Log Population

Gini Coefficient

1.027

$(0.82)$

$\begin{array}{lr}1.035 & (1.28) \\ 0.989 & (-0.38) \\ 1.120^{* * *} & (4.38)\end{array}$

$\begin{array}{lr}1.030 & (0.86) \\ 1.043 & (1.37) \\ & \\ 0.924^{* *} & (-2.88) \\ 1.002 & (0.07)\end{array}$

1.029

(0.93)

$1.070 * *$

$(2.66)$

$1.085^{* *} \quad(2.99)$

Absolute Poverty

$1.120^{* * *} \quad(4.38)$

1.019

(0.61)

1.013

$1.112^{* *} \quad(2.71)$

$1.031 \quad(1.00)$

$0.976 \quad(-0.84)$

Unemployment Rate

$1.002 \quad(0.07)$

$0.999 \quad(-0.03)$

$\begin{array}{ll}1.050 & (1.68) \\ 0.941 * & (-2.24)\end{array}$

$1.024 \quad(0.94)$

Public Assistance

TANF Maximum

Avg SNAP Benefit

Medicaid Eligibility

Avg Unemployment Benefit

State EITC

$\begin{array}{lrrrr}0.874^{* * *} & (-4.51) & 0.873^{* * *} & (-3.97) \\ 0.919^{* *} & (-3.09) & 0.892^{* * *} & (-4.12) \\ 1.017 & (0.66) & 1.016 & (0.66) \\ 0.921^{* *} & (-2.90) & 0.934^{*} & (-2.22) \\ 1.015 & (0.64) & 1.022 & (1.01)\end{array}$

\section{Random Effect:}

Intercept Variance

0.037

0.026

0.031

0.032

0.018

0.015

Level 2 Pseudo $\mathrm{R}^{2}$

0.075

AIC

323635.300

0.350

0.225

323621.100

323887.500

323630.400

323907.400

0.200

0.550

323613.100

323922.100

0.625

323632.200

323909.200

323612.800

323975.100

Note: Level $1 \mathrm{~N}=313,428$. Level $2 \mathrm{~N}=48$. The models also include individual-level independent variables and constants. OR=Odds ratio (factor change).

${ }^{*} \mathrm{p}<.05,{ }^{* *} \mathrm{p}<.01,{ }^{* * *} \mathrm{p}<.001$ (two-tailed). The Level 2 Pseudo $\mathrm{R}^{2}$ is the proportion reduction in the intercept variable from a model with only level 1 variables to the current model. The intercept variance for model with only level 1 variables is: 0.040 . 
TABLE 3B. X-Standardized Odds Ratios and (Z-Ratios) for Multilevel Binary Logistic Regression Models of Hypertension in 2007

\begin{tabular}{|c|c|c|c|c|c|c|c|c|c|c|c|c|}
\hline \multirow[b]{2}{*}{ Variable Name } & \multicolumn{2}{|c|}{ Model 1} & \multicolumn{2}{|c|}{$\underline{\text { Model } 2}$} & \multicolumn{2}{|c|}{ Model 3} & \multicolumn{2}{|c|}{ Model 4} & \multicolumn{2}{|c|}{ Model 5} & \multicolumn{2}{|c|}{ Model 6} \\
\hline & OR & Z-Ratio & OR & Z-Ratio & OR & Z-Ratio & OR & Z-Ratio & OR & Z-Ratio & OR & Z-Ratio \\
\hline
\end{tabular}

Fixed Effects:

Level 2 Variables

Log Population

Gini Coefficient

$1.021 \quad(0.70)$

$\begin{array}{ll}1.028 & (1.06) \\ 1.023 & (0.80) \\ 1.096^{* * *} & (3.66)\end{array}$

$\begin{array}{lr}1.023 & (0.71) \\ 1.068^{*} & (2.30) \\ & \\ 0.930^{* *} & (-2.62) \\ 1.004 & (0.12)\end{array}$

$\begin{array}{ll}1.021 & (0.72) \\ 1.046 & (1.52) \\ & \\ & \\ & \\ 1.048 & (1.72) \\ 0.956 & (-1.78)\end{array}$

$\begin{array}{lllr}1.059^{*} & (2.36) & 1.066^{*} & (2.42) \\ 1.044 & (1.92) & 1.014 & (0.56) \\ & & 1.081^{*} & (2.04) \\ & & 1.016 & (0.53) \\ & & 0.983 & (-0.60) \\ & & 1.005 & (0.24) \\ & & 1.038 & (1.48) \\ 0.888^{* * *} & (-4.17) & 0.879^{* * *} & (-3.87) \\ 0.918^{* *} & (-3.26) & 0.897^{* * *} & (-4.05) \\ 0.993 & (-0.31) & 0.990 & (-0.45) \\ 0.934^{*} & (-2.49) & 0.944 & (-1.93) \\ 1.034 & (1.46) & 1.042^{*} & (1.96)\end{array}$

State EITC

\section{Random Effect:}

Intercept Variance

0.032

0.025

0.027

0.028

0.017

0.014

Level 2 Pseudo $\mathrm{R}^{2}$

0.135

0.324 current model. The intercept variance for model with only level 1 variables is: 0.037 . 
TABLE 4A. X-Standardized Odds Ratios and (Z-Ratios) for Multilevel Binary Logistic Regression Models of Coronary Heart Disease in 2005

\begin{tabular}{|c|c|c|c|c|c|c|c|c|c|c|c|c|}
\hline \multirow[b]{2}{*}{ Variable Name } & \multicolumn{2}{|c|}{ Model 1} & \multicolumn{2}{|c|}{ Model 2} & \multicolumn{2}{|c|}{ Model 3} & \multicolumn{2}{|c|}{ Model 4} & \multicolumn{2}{|c|}{ Model 5} & \multicolumn{2}{|c|}{ Model 6} \\
\hline & OR & Z-Ratio & OR & Z-Ratio & OR & Z-Ratio & OR & Z-Ratio & OR & Z-Ratio & OR & Z-Ratio \\
\hline
\end{tabular}

Fixed Effects:

\section{Level 2 Variables}

Log Population

Gini Coefficient

$\begin{array}{rrrr}0.983 & (-0.51) & 0.989 & (-0.35) \\ 1.043 & (1.21) & 1.008 & (0.23) \\ & & 1.095^{* *} & (3.00)\end{array}$

$\begin{array}{ll}0.999 & (-0.03) \\ 1.058 & (1.69) \\ & \\ 0.918^{* *} & (-2.83) \\ 0.976 & (-0.65)\end{array}$

0.987

Absolute Poverty

GSP per Capita

Unemployment Rate

Medicaid Spending

Public Assistance

TANF Maximum

Avg SNAP Benefit

Medicaid Eligibility

Avg Unemployment Benefit

State EITC

$\begin{array}{rrrrlr}0.987 & (-0.39) & 1.033 & (1.04) & 1.061 & (1.67) \\ 1.034 & (0.95) & 1.028 & (0.96) & 1.004 & (0.13) \\ & & & & 1.115^{*} & (2.15) \\ & & & & 1.012 & (0.29) \\ & & & & 0.949 & (-1.40) \\ 1.033 & (1.00) & & & 0.993 & (-0.23) \\ 0.947 & (-1.81) & & & 1.004 & (0.12) \\ & & 0.911^{*} & (-2.52) & 0.918 & (-1.91) \\ & & 0.897^{* *} & (-3.17) & 0.876^{* * *} & (-3.65) \\ & & 0.992 & (-0.26) & 0.996 & (-0.12) \\ & & 0.913^{* *} & (-2.58) & 0.940 & (-1.57) \\ & & 1.007 & (0.23) & 1.015 & (0.53)\end{array}$

\section{Random Effect:}

Intercept Variance

0.041

0.034

0.034

0.037

0.026

0.023

Level 2 Pseudo $\mathrm{R}^{2}$

0.024

0.190

0.190

0.119

0.381

0.452 current model. The intercept variance for model with only level 1 variables is: 0.042 . 
TABLE 4B. X-Standardized Odds Ratios and (Z-Ratios) for Multilevel Binary Logistic Regression Models of Coronary Heart Disease in 2007

\begin{tabular}{|c|c|c|c|c|c|c|c|c|c|c|c|c|}
\hline \multirow[b]{2}{*}{ Variable Name } & \multicolumn{2}{|c|}{ Model 1} & \multicolumn{2}{|c|}{ Model 2} & \multicolumn{2}{|c|}{ Model 3} & \multicolumn{2}{|c|}{ Model 4} & \multicolumn{2}{|c|}{ Model 5} & \multicolumn{2}{|c|}{ Model 6} \\
\hline & OR & Z-Ratio & OR & Z-Ratio & OR & Z-Ratio & OR & Z-Ratio & OR & Z-Ratio & OR & Z-Ratio \\
\hline
\end{tabular}

Fixed Effects:

\section{Level 2 Variables}

Log Population

Gini Coefficient

$\begin{array}{llll}1.018 & (0.53) & 1.024 & (0.77) \\ 1.039 & (1.14) & 1.007 & (0.21) \\ & & 1.083^{* *} & (2.70)\end{array}$

$\begin{array}{ll}1.037 & (1.01) \\ 1.054 & (1.64) \\ & \\ 0.918^{* *} & (-2.93) \\ 0.973 & (-0.76)\end{array}$

$\begin{array}{ll}1.019 & (0.58) \\ 1.027 & (0.79) \\ & \\ & \\ 1.043 & (1.35) \\ 0.951 & (-1.75)\end{array}$

1.059

(1.86)

$1.088^{*}$

1.011

Absolute Poverty

GSP per Capita

Unemployment Rate

Medicaid Spending

Public Assistance

TANF Maximum

Avg SNAP Benefit

Medicaid Eligibility

Avg Unemployment Benefit

State EITC

$\begin{array}{lrlr} & & 1.104^{*} & (2.03) \\ & & 0.985 & (-0.40) \\ & & 0.939 & (-1.75) \\ & & 0.996 & (-0.13) \\ & & 1.006 & (0.19) \\ 0.888^{* * *} & (-3.31) & 0.895^{* *} & (-2.59) \\ 0.896^{* * *} & (-3.31) & 0.882^{* * *} & (-3.63) \\ 1.007 & (0.24) & 1.011 & (0.38) \\ 0.941 & (-1.78) & 0.980 & (-0.54) \\ 1.013 & (0.46) & 1.025 & (0.91)\end{array}$

\section{Random Effect:}

Intercept Variance

0.038

0.033

0.031

0.034

0.025

0.021

Level 2 Pseudo $\mathrm{R}^{2}$

0.050

0.175

149715.200

0.225

AIC

149975.300

0.175
149710.400
149981.400
149711.300
149993.100
0.150
149714.700
149996.500
0.375
149706.800
150021.100

0.475

149709.600

150078.100

Note: Level $1 \mathrm{~N}=376,602$. Level $2 \mathrm{~N}=48$. The models also include individual-level independent variables and constants. OR=Odds ratio (factor change).

${ }^{*} \mathrm{p}<.05,{ }^{* *} \mathrm{p}<.01,{ }^{* * *} \mathrm{p}<.001$ (two-tailed). The Level 2 Pseudo $\mathrm{R}^{2}$ is the proportion reduction in the intercept variable from a model with only level 1 variables to the current model. The intercept variance for model with only level 1 variables is: 0.040 . 